\title{
Comparison of Multilocus Variable-Number Tandem-Repeat Analysis with Multilocus Sequence Typing and Pulsed-Field Gel Electrophoresis for Enterococcus faecalis
}

\author{
EWA SADOWY ${ }^{1 *}$, ALEKSANDRA SIENKKO $^{2}$ and WALERIA HRYNIEWICZ ${ }^{1}$ \\ ${ }^{1}$ National Medicines Institute, Warsaw, Poland \\ ${ }^{2}$ Epidemiological Response Centre of the Polish Armed Forces, Warsaw, Poland \\ Received 2 August 2011, revised 6 October 2011, accepted 10 October 2011
}

\begin{abstract}
Enterococcus faecalis represents recently an important etiological agent of health care-associated infections (HAIs) and there is a need for evaluation and comparison of typing methods available for this microorganism. We tested multilocus VNTR (variable-number tandem repeats) analysis (MLVA) on a well-characterized collection of 153 clinical isolates of $E$. faecalis, corresponding to 52 multilocus sequence types and 67 pulsed-field gel electrophoresis (PFGE) profiles. MLVA showed high discriminatory power, discerning 111 different types (diversity index equal 98.9\%). The concordance MLVA/MLST and MLVA/PFGE was 0.95 and 0.74 , respectively. High discriminatory power of MLVA indicates its utility for local epidemiology such as outbreak investigation, and for differentiation of clones defined by other methods.
\end{abstract}

Ke y words: E. faecalis clones, MLST, PFGE, VNTR

Enterococci, common and harmless colonizers of human and animal gastrointestinal tract, nowadays represent an important factor of health care-associated infections (HAIs) including invasive infections (mostly endocarditis and bacteraemia) and infections of urinary tract and post-operative site (European Centre for Disease Prevention and Control, 2010; Sydnor and Perl, 2011). The number of patients at risk of enterococcal HAIs is currently increasing, including especially persons with haematological malignancies, and receiving bone marrow and solid-organ transplants (Sydnor and Perl, 2011). Among enterococci causing HAIs, Enterococcus faecalis is the predominant species (Jett et al., 1994) and its intrinsic lack of susceptibility to several antimicrobial agents, together with an acquisition of additional resistance traits posses an increasing challenge to therapy (Arias and Murray, 2008). There is an obvious need for the development and evaluation of molecular typing methods for both epidemiological studies of hospital E. faecalis outbreaks, and fast identification of high-risk enterococcal complexes, associated with elevated epidemic properties and antimicrobial resistance (Leavis et al., 2006; RuizGarbajosa et al., 2007).

For E. faecalis, the "gold-standard" technique of pulsed-field gel electrophoresis (PFGE) of macro- restricted bacterial DNA is widely used in outbreak studies. In global epidemiology, PFGE is now being more and more widely replaced by sequence-based methods that allow for unambiguous identification of isolates, easy data accumulation and comparison. A few such schemes have been described, including the most popular approach of multilocus sequence typing (MLST) with seven house-keeping loci (Ruiz-Garbajosa et al., 2007). Another typing method, multilocus variable-number tandem-repeat (VNTR) analysis (MLVA) has also been proposed for E. faecalis (Titze-de-Almeida et al., 2004) as a fast and cheap alternative to PFGE and MLST. MLVA indexes variation of number of repeats present in bacterial genomes and thus also provides an unambiguous, portable identification of an isolate (van Belkum, 2007). The aim of this study was to evaluate the discriminatory power and typability of MLVA using an extensive collection of isolates characterized previously by MLST and PFGE (Kawalec et al., 2007).

A hundred and fifty three isolates of E. faecalis derived from colonization, as well as from invasive and non-invasive infections of hospitalized patients from 42 medical centres in Poland during 1996-2005 (Kawalec et al., 2007) were used in the current analysis. These isolates represented 67 different PFGE profiles and 52 different sequence types (STs); the latter were

\footnotetext{
* Corresponding author: E. Sadowy, Department of Molecular Microbiology, National Medicines Institute, ul. Chełmska 30/34, 00-725 Warsaw, Poland; phone: +48 2285143 88; fax: +48 2284129 49; e-mail: ewasadowy@cls.edu.pl
} 
grouped into five clonal groups (CC21, CC 40, CC87, group of ST88/89, group of ST132/141) and 42 singletons by the eBURST analysis (Feil et al., 2004). MLVA was performed as described (Titze-de-Almeida et al., 2004), according to the scheme including seven VNTR loci: ace (the $\mathrm{B}$ region), esp (the $\mathrm{A}$ and $\mathrm{C}$ regions), efa2, efa3, efa5, and efa6. The data were then analyzed by the eBURST analysis (Feil et al., 2004). The diversity index (DI) with 95\% confidence intervals was calculated as described by others (Grundman et al., 2001); the Wallace coefficient was determined using the site http://darwin.phyloviz.net/ComparingPartitions/ (last accessed on the $4^{\text {th }}$ of July 2011).

From four to eight variants were found for particular VNTR loci and among these only the aceB locus was $100 \%$ typable (Table I). This gene is known to be ubiquitous in E. faecalis (Nallapareddy et al., 2000). A very good typability was found also for efa6 (99.3\% i.e. a single isolate was negative). For the other five loci espC, espA, efa2, efa 3 and efa5, typability was $73.9 \%$, $68.0 \%, 50.3 \%, 46.4 \%$ and $86.3 \%$, respectively; such incomplete MLVA profiles were found also in other studies on E. faecalis (Titze-de-Almeida et al., 2004; Wałecka et al., 2009; Xavier et al., 2010). Interestingly, the complete MLVA profiles were observed mostly for isolates from infections than from carriage or hospital environment (Fisher exact one-tailed test, $\mathrm{p}=0.035$ ), which is in agreement with the fact that the former isolates are enriched in virulence factors (Shankar et al., 1999). All strains negative for both espC and espA VNTR lacked the esp gene (Kawalec et al., 2007). Apart from the total absence of the gene, the observed lack of PCR product for certain VNTR loci may also be due to sequence polymorphisms that hinder annealing of primers, a deletion of the whole repeat region from a gene, as reported for $e s p_{\mathrm{Efm}}$ (Leavis et al., 2004), or insertion of a mobile element into a locus (Koeck et al., 2005). Incomplete MLVA profiles were observed also for other species, e.g. for Enterococcus faecium (Top et al., 2008; Werner et al., 2007) and Streptococcus pneumoniae (Koeck et al., 2005).

A hundred and eleven different combinations of VNTR variants were observed in the studied group, corresponding to 111 MLVA types (MTs), numbered consecutively $39-149$ (i.e., 1.4 isolate/MT; Table I) that all represented new profiles compared to the $38 \mathrm{MTs}$ described in the earlier study (Titze-de-Almeida et al., 2004). The DI for MLVA was equal $98.9 \%$ (CI; 98.299.6\%); the DIs for MLST and PFGE calculated on the basis of previous results (Kawalec et al., 2007) were both significantly lower and showed similar values of 94.0\% (CI, 92.2-95.9\%) and 92.4\% (CI, 89.7-95.0\%), respectively. A lower diversity of isolates was observed in the study on E. faecalis in four Brazilian hospitals where 38 MTs and 31 PFGE types were found among 83
Table I

MTs and VNTR loci profiles of Polish clinical isolates of E. faecalis

\begin{tabular}{|c|c|c|c|c|c|c|c|}
\hline $\mathrm{MT}^{\mathrm{a}}$ & $a c e B$ & espC & $\operatorname{esp} A$ & efa2 & efa3 & efa5 & efa6 \\
\hline 38 & 4 & $\mathrm{nt}$ & $\mathrm{nt}$ & 6 & 3 & 4 & 4 \\
\hline 39 & 4 & 6 & 2 & 6 & 3 & 5 & 4 \\
\hline 40 & 4 & 7 & $\mathrm{nt}$ & 6 & 3 & 5 & 4 \\
\hline 41 & 4 & 5 & $\mathrm{nt}$ & 6 & 3 & 5 & 4 \\
\hline 42 & 4 & 1 & 2 & 6 & 3 & 5 & 4 \\
\hline 43 & 4 & 4 & 2 & 6 & 3 & 5 & 4 \\
\hline 44 & 4 & 3 & 2 & 6 & 3 & 5 & 4 \\
\hline 45 & 4 & nt & 2 & 6 & 3 & 5 & 4 \\
\hline 46 & 4 & nt & 2 & 5 & 3 & 5 & 4 \\
\hline 47 (3) & 4 & 7 & 2 & 5 & 3 & 5 & 3 \\
\hline 48 & 2 & 6 & 2 & 5 & 3 & 5 & 3 \\
\hline 49 & 2 & 6 & 2 & 5 & $\mathrm{nt}$ & 3 & 3 \\
\hline 50 & 4 & 7 & 1 & 5 & 2 & 4 & 3 \\
\hline 51 & 4 & nt & $\mathrm{nt}$ & 5 & 1 & 4 & 3 \\
\hline $52(2)$ & 4 & 7 & 1 & 5 & $\mathrm{nt}$ & 4 & 3 \\
\hline 53 & 4 & 7 & 1 & 5 & 2 & 3 & 3 \\
\hline 54 & 4 & nt & 2.5 & 5 & $\mathrm{nt}$ & 5 & 3 \\
\hline 55 & 2 & nt & 3 & 8 & $\mathrm{nt}$ & 7 & 3 \\
\hline 56 & 2 & 5 & 1 & $\mathrm{nt}$ & $\mathrm{nt}$ & 7 & 3 \\
\hline $57(2)$ & 2 & 6 & 1 & nt & $\mathrm{nt}$ & 7 & 3 \\
\hline $58(6)$ & 4 & 6 & 2 & nt & $\mathrm{nt}$ & 5 & 3 \\
\hline $59(13)$ & 4 & 7 & 2 & $\mathrm{nt}$ & $\mathrm{nt}$ & 5 & 3 \\
\hline $60(3)$ & 2 & 7 & 2 & $\mathrm{nt}$ & 2 & 5 & 3 \\
\hline 61 & 2 & 4 & 2 & $\mathrm{nt}$ & 2 & 5 & 3 \\
\hline 62 & 2 & 7 & 2 & $\mathrm{nt}$ & 2 & 3 & 3 \\
\hline 63 & 2 & 7 & 2 & nt & 2 & 4 & 3 \\
\hline 64 & 4 & 5 & 2 & $\mathrm{nt}$ & $\mathrm{nt}$ & 5 & 3 \\
\hline 65 & 4 & 5 & 2 & $\mathrm{nt}$ & $\mathrm{nt}$ & 6 & 3 \\
\hline 66 & 4 & 7 & 2 & nt & $\mathrm{nt}$ & 5 & $\mathrm{nt}$ \\
\hline 68 & 4 & 7 & $\mathrm{nt}$ & nt & $\mathrm{nt}$ & 4 & 3 \\
\hline 69 & 4 & 7 & nt & 6 & 3 & 4 & 4 \\
\hline $70(3)$ & 4 & 7 & 2 & nt & $\mathrm{nt}$ & 4 & 3 \\
\hline 71 & 4 & 6 & nt & $\mathrm{nt}$ & $\mathrm{nt}$ & 5 & 3 \\
\hline 72 & 2 & 5 & $\mathrm{nt}$ & 7 & $\mathrm{nt}$ & 7 & 3 \\
\hline 73 & 5 & 7 & 2 & nt & $\mathrm{nt}$ & 3 & 3 \\
\hline 74 & 4 & 8 & 2 & 5 & 3 & 5 & 3 \\
\hline 75 & 4 & 6 & 2 & 4 & 3 & 5 & 3 \\
\hline 76 & 2 & 6 & $\mathrm{nt}$ & 7 & 2 & 3 & 3 \\
\hline 77 & 3 & 4 & 2 & $\mathrm{nt}$ & $\mathrm{nt}$ & nt & 3 \\
\hline 78 & 4 & 5 & 2 & $\mathrm{nt}$ & $\mathrm{nt}$ & 4 & 3 \\
\hline 79 & 4 & 6 & nt & 7 & 2 & 5 & 2 \\
\hline 80 & 4 & 5 & $\mathrm{nt}$ & 6 & 2 & 6 & 3 \\
\hline 81 & 4 & 6 & nt & 8 & 1 & 3 & 3 \\
\hline 82 & 1 & nt & nt & 7 & 1 & 5 & 3 \\
\hline 83 & 4 & 8 & 2 & $\mathrm{nt}$ & $\mathrm{nt}$ & 3 & 4 \\
\hline 84 & 2 & nt & nt & 8 & $\mathrm{nt}$ & 6 & 2 \\
\hline 85 & 2 & nt & nt & $\mathrm{nt}$ & $\mathrm{nt}$ & 6 & 3 \\
\hline 86 & 2 & nt & nt & $\mathrm{nt}$ & 3 & 6 & 3 \\
\hline
\end{tabular}




\begin{tabular}{|c|c|c|c|c|c|c|c|}
\hline $\mathrm{MT}^{\mathrm{a}}$ & $a c e B$ & espC & espA & efa2 & efa3 & efa5 & efa6 \\
\hline 87 & 4 & nt & $\mathrm{nt}$ & 6 & 3 & 5 & 2 \\
\hline 88 & 4 & $\mathrm{nt}$ & $\mathrm{nt}$ & 6 & 3 & $\mathrm{nt}$ & 3 \\
\hline 89 & 3 & $\mathrm{nt}$ & $\mathrm{nt}$ & $\mathrm{nt}$ & $\mathrm{nt}$ & 6 & 3 \\
\hline 90 & 3 & 7 & $\mathrm{nt}$ & $\mathrm{nt}$ & 3 & 6 & 3 \\
\hline 91 & 3 & 9 & 4 & $\mathrm{nt}$ & 3 & 6 & 3 \\
\hline 92 & 3 & 9 & 4 & $\mathrm{nt}$ & $\mathrm{nt}$ & 6 & 3 \\
\hline $93(2)$ & 3 & 7 & 4 & $\mathrm{nt}$ & $\mathrm{nt}$ & 6 & 3 \\
\hline $94(4)$ & 3 & 7 & 1 & 7 & $\mathrm{nt}$ & 5 & 3 \\
\hline $95(2)$ & 3 & 7 & 2 & 8 & $\mathrm{nt}$ & 5 & 3 \\
\hline 96 & 3 & nt & 2 & 7 & $\mathrm{nt}$ & 5 & 3 \\
\hline $97(3)$ & 3 & 6 & 2 & 8 & $\mathrm{nt}$ & 5 & 3 \\
\hline $98(2)$ & 3 & $\mathrm{nt}$ & $\mathrm{nt}$ & 7 & nt & 5 & 3 \\
\hline 99 & 3 & nt & 2.5 & 6 & nt & 5 & 3 \\
\hline 100 & 3 & nt & 2 & 6 & $\mathrm{nt}$ & 5 & 3 \\
\hline $101(2)$ & 3 & nt & $\mathrm{nt}$ & 6 & $\mathrm{nt}$ & 5 & 3 \\
\hline $102(2)$ & 3 & nt & $\mathrm{nt}$ & 5 & $\mathrm{nt}$ & 5 & 3 \\
\hline 103 & 3 & 6 & $\mathrm{nt}$ & 5 & $\mathrm{nt}$ & 5 & 3 \\
\hline $104(2)$ & 4 & 6 & 3 & $\mathrm{nt}$ & 3 & $\mathrm{nt}$ & 3 \\
\hline 105 & 4 & 6 & 3 & 2.5 & 3 & 7 & 3 \\
\hline 106 & 5 & 6 & 1 & $\mathrm{nt}$ & 3 & 7 & 3 \\
\hline 107 & 5 & 6 & 3 & $\mathrm{nt}$ & 3 & $\mathrm{nt}$ & 3 \\
\hline 108 & 3 & 6 & 3 & 7 & 3 & $\mathrm{nt}$ & 3 \\
\hline 109 & 3 & 6 & 3 & 9 & 4 & $\mathrm{nt}$ & 3 \\
\hline 110 & 4 & 6 & 3 & 9 & 3 & $\mathrm{nt}$ & 3 \\
\hline 111 & 4 & $\mathrm{nt}$ & 5 & $\mathrm{nt}$ & 3 & $\mathrm{nt}$ & 3 \\
\hline 112 & 4 & 5 & 4 & 8 & 3 & 7 & 3 \\
\hline 113 & 3 & $\mathrm{nt}$ & $\mathrm{nt}$ & $\mathrm{nt}$ & 3 & $\mathrm{nt}$ & 3 \\
\hline 114 & 3 & 3 & 4 & $\mathrm{nt}$ & 3 & 5 & 3 \\
\hline 115 & 3 & $\mathrm{nt}$ & 2 & $\mathrm{nt}$ & 3 & 5 & 3 \\
\hline 116 & 3 & 6 & 5 & $\mathrm{nt}$ & 3 & 5 & 3 \\
\hline 117 & 3 & 5 & 5 & 2.5 & 3 & $\mathrm{nt}$ & 3 \\
\hline 118 & 3 & 6 & 3 & $\mathrm{nt}$ & 3 & 5 & 3 \\
\hline $119(2)$ & 3 & 5 & $\mathrm{nt}$ & $\mathrm{nt}$ & 3 & $\mathrm{nt}$ & 3 \\
\hline $120(2)$ & 3 & 5 & 4 & $\mathrm{nt}$ & 3 & $\mathrm{nt}$ & 3 \\
\hline 121 & 3 & 5 & 4 & 2.5 & 3 & $\mathrm{nt}$ & 3 \\
\hline $122(2)$ & 3 & 5 & 5 & $\mathrm{nt}$ & 3 & $\mathrm{nt}$ & 3 \\
\hline 123 & 3 & 6 & 4 & $\mathrm{nt}$ & 3 & 3 & 3 \\
\hline $124(2)$ & 3 & 3 & 2 & $\mathrm{nt}$ & $\mathrm{nt}$ & 1 & 3 \\
\hline 125 & 4 & $\mathrm{nt}$ & $\mathrm{nt}$ & 6 & 2 & 7 & 3 \\
\hline $126(2)$ & 4 & $\mathrm{nt}$ & $\mathrm{nt}$ & $\mathrm{nt}$ & 2 & 7 & 4 \\
\hline 127 & 4 & 6 & $\mathrm{nt}$ & $\mathrm{nt}$ & 2 & 7 & 4 \\
\hline 128 & 4 & 6 & 2 & 5 & $\mathrm{nt}$ & 5 & 3 \\
\hline 129 & 4 & 7 & 2 & 5 & $\mathrm{nt}$ & 5 & 3 \\
\hline 130 & 3 & 7 & 2 & $\mathrm{nt}$ & $\mathrm{nt}$ & 5 & 3 \\
\hline 131 & 3 & 5 & nt & 5 & $\mathrm{nt}$ & 5 & 3 \\
\hline 132 & 2 & 6 & $\mathrm{nt}$ & $\mathrm{nt}$ & 2 & 3 & 3 \\
\hline 133 & 2 & 5 & 3 & $\mathrm{nt}$ & 2 & 3 & 4 \\
\hline 134 & 4 & $\mathrm{nt}$ & nt & 6 & $\mathrm{nt}$ & 7 & 3 \\
\hline
\end{tabular}

\begin{tabular}{|l|c|c|c|c|c|c|c|}
\hline $\mathrm{MT}^{\mathrm{a}}$ & $a c e B$ & $e s p C$ & $e s p A$ & $e f a 2$ & $e f a 3$ & $e f a 5$ & $e f a 6$ \\
\hline 135 & 4 & $\mathrm{nt}$ & $\mathrm{nt}$ & $\mathrm{nt}$ & $\mathrm{nt}$ & 5 & 4 \\
\hline 136 & 3 & $\mathrm{nt}$ & $\mathrm{nt}$ & 5 & $\mathrm{nt}$ & $\mathrm{nt}$ & 2 \\
\hline 137 & 2 & 7 & 2 & 3.5 & $\mathrm{nt}$ & 3 & 1 \\
\hline 138 & 4 & 6 & $\mathrm{nt}$ & 3.5 & 2 & 6 & 2 \\
\hline 139 & 4 & 6 & $\mathrm{nt}$ & 3.5 & $\mathrm{nt}$ & 6 & 2 \\
\hline 140 & 3 & $\mathrm{nt}$ & 2 & 5 & 1 & 4 & 3 \\
\hline 141 & 3 & $\mathrm{nt}$ & $\mathrm{nt}$ & $\mathrm{nt}$ & 1 & $\mathrm{nt}$ & 3 \\
\hline 142 & 3 & $\mathrm{nt}$ & $\mathrm{nt}$ & 6 & $\mathrm{nt}$ & 7 & 3 \\
\hline $143(2)$ & 3 & $\mathrm{nt}$ & $\mathrm{nt}$ & 8 & $\mathrm{nt}$ & 5 & 3 \\
\hline 144 & 3 & $\mathrm{nt}$ & $\mathrm{nt}$ & 6 & 3 & 5 & 3 \\
\hline 145 & 3 & 6 & 2 & $\mathrm{nt}$ & $\mathrm{nt}$ & 5 & 3 \\
\hline 146 & 4 & $\mathrm{nt}$ & $\mathrm{nt}$ & 8 & $\mathrm{nt}$ & 5 & 3 \\
\hline 147 & 3 & $\mathrm{nt}$ & $\mathrm{nt}$ & 5 & 2 & 5 & 3 \\
\hline 148 & 4 & $\mathrm{nt}$ & $\mathrm{nt}$ & 3.5 & 2 & 5 & 4 \\
\hline 149 & 2 & 5 & 2 & 5 & $\mathrm{nt}$ & $\mathrm{nt}$ & 3 \\
\hline
\end{tabular}

${ }^{a}$ Number of isolates, if bigger than one, given in brackets; nt, nontypable.

isolates (2.4 isolates/MT); the DI for MLVA of this group was 93.3\% (Titze-de-Almeida et al., 2004). A similar study revealed 40 MTs among 56 isolates (i.e., 1.4 isolate/MT) from two Polish hospitals (Wałecka et al., 2009). The overall concordance of the compared typing methods, measured by the Wallace coefficient was 0.95 for MLVA/MLST and 0.74 for MLVA/PFGE. In an earlier study, the concordance for MLVA/PFGE was reported as 0.90 for main five clusters of isolates (Titze-de-Almeida et al., 2004).

The eBURST analysis performed on the MLVA profiles delimited 15 clonal groups and 37 singletons (Fig. 1). Three major groups such as MLVA-59 (the naming of the MLVA-defined groups according to the presumable ancestral MT), MLVA-101 and MLVA-119 included 17, 14 and 7 MTs, respectively, and 41, 18 and 10 isolates, respectively. The comparison of MLVA and MLST grouping (Fig. 1) revealed certain cases of incongruence between the two methods. The principal group MLVA-59 was associated with three clonal groups defined by MLST (CC40, CC21, group of ST88/89) and singleton STs 26, 55, 59 and 136. Another major group, MLVA-101, grouped isolates belonging to four groups defines by MLST and five singleton STs. On the other hand, known HIRECCs of E. faecalis (RuizGarbajosa et al., 2006; Kawalec et al., 2007) such as CC2 (represented here by ST6), CC9 and CC87 each included several MTs; the most divergent CC87 contained three MLVA groups and 10 MLVA singletons, i.e. altogether 20 different MTs. Such high variability of MTs within established enterococcal HIRECCs makes it difficult to use MLVA for their identification. Although other typing methods of E. faecalis, such as PFGE and 


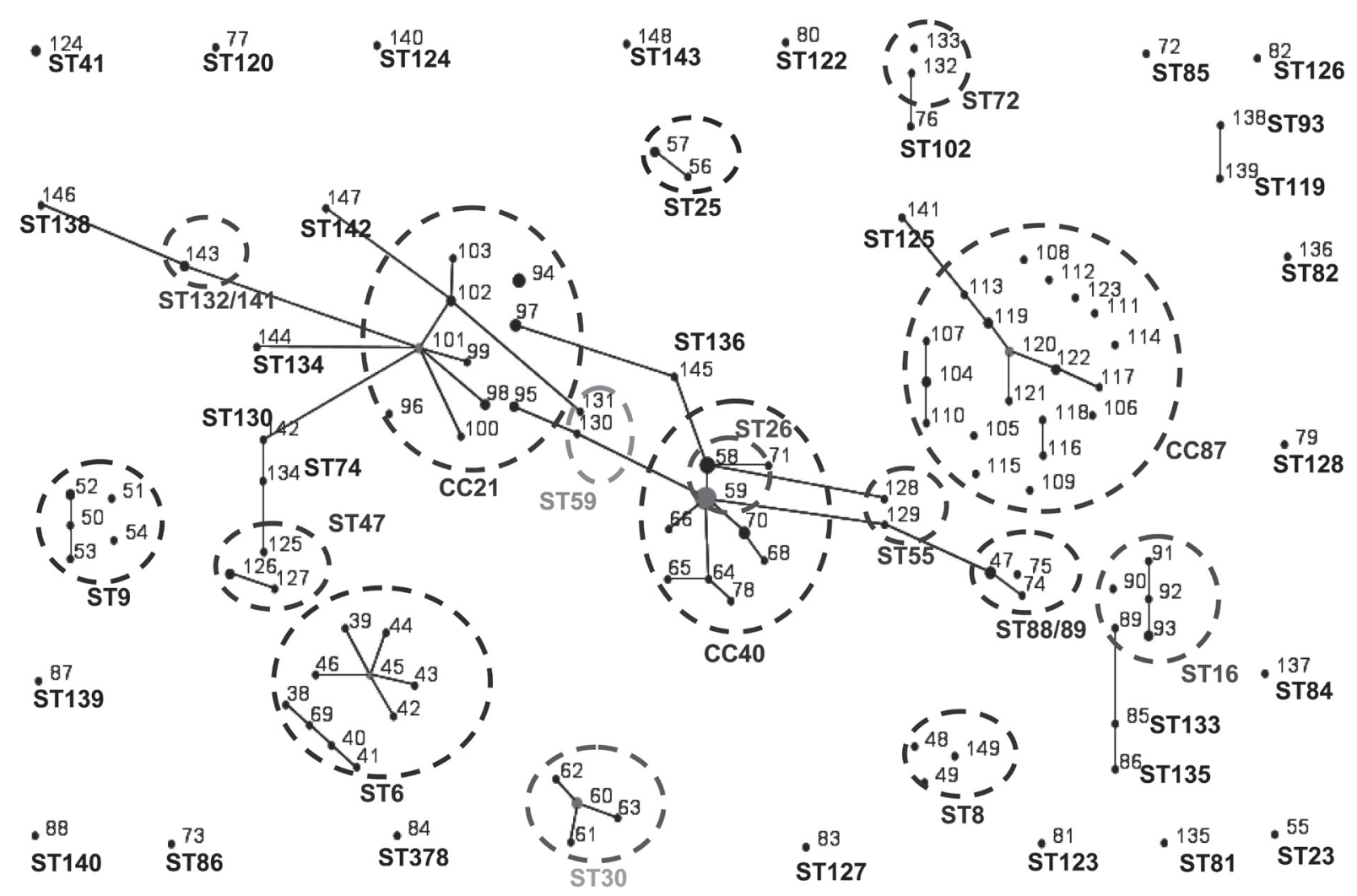

Fig. 1. Clonal relationships among E. faecalis according to MLVA and eBURST analysis, compared to MLST results. Solid circles, MTs with size proportional to the number of isolates; light grey circles, presumable ancestors of clonal groups; lines, SLV links; open coloured circles, main STs and clonal groups as defined by MLST. The eBURST output was extensively manually edited.

sequence-based typing methods generally show a good agreement, some examples of their incongruence, presumably resulting from recombination typical for this species were also found (Nallapareddy et al., 2002; Kawalec et al., 2007; Chowdhury et al., 2009).

Very high discriminatory power of MLVA and observed incongruence with other typing methods, such as PFGE and MLST, observed in the current study may have resulted from the selection of isolates. Our collection was derived from several centres over a long period of time while other studies (Titze-de-Almeida et al., 2004; Wałecka et al., 2009) used isolates from more limited areas and time span. MLVA markers are likely the ones evolving faster than house-keeping loci in MLST. The VNTR loci, selected for the current E. faecalis MLVA scheme encode surface-located factors that presumably are under strong selective pressure. The change of repeat number during infection was observed for the alpha $\mathrm{C}$ protein of the Alp-like protein family in Streptococcus agalactiae, resulting in the escape from the host immunological system (Madoff et al., 1996). The VNTR loci used for E. faecalis MLVA encode Esp (enterococcal surface protein), a partial homolog of the Alp-like proteins (Hendrickx et al., 2009), Ace (adhesin to collagen from E. faecalis; Hendrickx et al., 2009), the Efa2, Efa3 and Efa5 proteins that belong to the ABC superfamily of membrane channel-forming proteins
(Khwaja et al., 2005) and the Efa6 protein of unknown function that is also a surface protein (da Silva Ruivo, 2008). It has to be also considered that in the case of MLVA some similarities in the typing patterns, including the loss of typability at a given loci might have arisen by convergent evolution, thus resulting in incongruence with other methods. In conclusion, this is, to our knowledge, a first report on comparison of MLVA and MLST for E. faecalis. Our study indicates MLST as the method of choice for long-term epidemiology while MLVA appears to be over-discriminatory for such studies. The MLVA-based identification of enterococcal HIRECCs should be treated with caution as examples of incongruence between MLVA and MLST as well as high variability of MTs within known HIRECCs were observed. The high discriminatory power of MLVA indicates the utility of this method for studies on hospital outbreaks and for further differentiation of the most important clones, which may be difficult with other typing methods.

\section{Acknowledgements}

This work was supported by a grant ACE from the European Union VI Framework Program under the contract LSHECT-2007-037410 and a complementary founding from the Ministry of Science and Higher Education, Poland (decision 937/6. PR $\mathrm{UE} / 2009 / 7)$. 


\section{Literature}

Arias C.A. and B.E. Murray. 2008. Emergence and management of drug-resistant enterococcal infections. Exp. Rev. Anti. Infect. Ther. 6: 637-655.

Chowdhury S.A., C.A. Arias, S.R. Nallapareddy, J. Reyes, R.J. Willems and B.E. Murray. 2009. A tri-locus sequence typing scheme for hospital epidemiology and subspecies differentiation of an important nosocomial pathogen, Enterococcus faecalis. J. Clin. Microbiol. 47: 2713-2719.

da Silva Ruivo M.I. 2008. Estudo da disseminação de Enterococcus faecalis vanA+ em diferentes ambientes. M.S. thesis, Universidade de Lisboa, Portugal.

European Centre for Disease Prevention and Control. Annual Epidemiological Report on Communicable Diseases in Europe 2010. 2010. Stockholm: ECDC. http://www.ecdc.europa.eu/en/ publications/Publications/1011_SUR_Annual_Epidemiological_ Report_on_Communicable_Diseases_in_Europe.pdf. (7th July 2011, date last accessed).

Feil E.J., B.C. Li, D.M. Aanensen, W.P. Hanage and B.G. Spratt. 2004. eBURST: inferring patterns of evolutionary descent among clusters of related bacterial genotypes from multilocus sequence typing data. J. Bacteriol. 186: 1518-1530.

Grundman H., S. Hori and G. Tanner. 2001. Determining confidence intervals when measuring genetic diversity and the discriminatory abilities of typing methods for microorganisms. J. Clin. Microbiol. 39:4190-4192.

Hendrickx A.P., R.J. Willems, M.J. Bonten and W. van Schaik. 2009. LPxTG surface proteins of enterococci. Trends Microbiol. 17: 423-430. Jett B.D., M.M. Huycke and M.S. Gilmore. 1994. Virulence of enterococci. Clin. Microb. Rev. 7: 462-478.

Kawalec M., Z. Pietras, E. Danilowicz, A. Jakubczak, M. Gniadkowski, W. Hryniewicz and R.J. Willems. 2007. Clonal structure of Enterococcus faecalis isolated from Polish hospitals: characterization of epidemic clones. J. Clin. Microbiol. 45: 147-153.

Khwaja M., Q. Ma and M.H. Saier Jr. 2005. Topological analysis of integral membrane constituents of prokaryotic ABC efflux systems. Res. Microbiol. 156:270-277.

Koeck J.L., B.M. Njanpop-Lafourcade, S. Cade, E. Varon, L. Sangare, S. Valjevac, G. Vergnaud and C. Pourcel. 2005. Evaluation and selection of tandem repeat loci for Streptococcus pneumoniae MLVA strain typing. BMC Microbiol. 5: 66.

Leavis H., J. Top, N. Shankar, K. Borgen, M. Bonten, J. van Embden and R.J. Willems. 2004. A novel putative enterococcal pathogenicity island linked to the esp virulence gene of Enterococcus faecium and associated with epidemicity. J. Bacteriol. 186:672-682.

Leavis, H.L., M.J. Bonten and R.J. Willems. 2006. Identification of high-risk enterococcal clonal complexes: global dispersion and antibiotic resistance. Curr. Opin. Microbiol. 9: 454-460.
Madoff L.C., J.L. Michel, E.W. Gong, D.E. Kling and D.L. Kasper. 1996. Group B streptococci escape host immunity by deletion of tendem repeat elements of the alpha C protein. Proc. Natl. Acad. Sci. USA 93: 4131-4136.

Nallapareddy S.R., K.V. Singh, R.W. Duh, G.M. Weinstock and B.E. Murray. 2000. Diversity of ace, a gene encoding a microbial surface component recognizing adhesive matrix molecules, from different strains of Enterococcus faecalis and evidence for production of Ace during human infections. Infect. Immun. 68: 5210-7.

Nallapareddy S.R., R.W. Duh, K.V. Singh and B.E. Murray. 2002. Molecular typing of selected Enterococcus faecalis isolates: pilot study using multilocus sequence typing and pulsed-field gel electrophoresis. J. Clin. Microbiol. 40: 868-876.

Ruiz-Garbajosa P., M.J. Bonten, D.A. Robinson, J. Top, S.R. Nallapareddy, C. Torres, T.M. Coque, R. Cantón, F. Baquero, B.E. Murray, R. del Campo and R.J. Willems. 2006. Multilocus sequence typing scheme for Enterococcus faecalis reveals hospital-adapted genetic complexes in a background of high rates of recombination. J. Clin. Microbiol. 44: 2220-2228.

Shankar V., A.S. Baghdayan, M.M. Huycke, G. Lindahl and M.S. Gilmore. 1999. Infection-derived Enterococcus faecalis strains are enriched in esp, a gene encoding a novel surface protein. Infect. Immun. 67: 193-200.

Sydnor E.R. and T.M. Perl. 2011. Hospital epidemiology and infection control in acute-care settings. Clin. Microbiol. Rev. 24: 141-173.

Titze-de-Almeida, R., R.J. Willems, J. Top, I.P. Rodrigues, R.F. Ferreira 2nd, H. Boelens, M.C. Brandileone, R.C. Zanella, M.S. Felipe and A. van Belkum. 2004. Multilocus variable-number tandem-repeat polymorphism among Brazilian Enterococcus faecalis strains. J. Clin. Microbiol. 42: 4879-4881.

Top J., Willems R., van der Velden S., Asbroek M. and Bonten M. 2008. Emergence of clonal complex 17 Enterococcus faecium in The Netherlands. J. Clin. Microbiol. 46: 214-219.

van Belkum A. 2007. Tracing isolates of bacterial species by multilocus variable number of tandem repeat analysis (MLVA). FEMS Immunol. Med. Microbiol. 49: 22-27.

Wałecka E., J. Bania, E. Dworniczek and M. Ugorski. 2009. Genotypic characterization of hospital Enterococcus faecalis strains using multiple-locus variable-number tandem-repeat analysis. Lett. Appl. Microbiol. 49: 79-84.

Werner G., I. Klare and W. Witte. 2007. The current MLVA typing scheme for Enterococcus faecium is less discriminatory than MLST and PFGE for epidemic-virulent, hospital-adapted clonal types. BMC Microbiol. 7: 28.

Xavier D.B., A.H. Rosa, H. dos Santos Sena, D.S. Teixeira, C. Tomaz and R. Titze-de-Almeida. 2010. Absence of intestinal colonization by vancomycin resistant enterococci in nonhuman primates. Pesq. Vet. Bras. 30: 491-496. 